\title{
Dynamical Analysis of Ladle Crane
}

\author{
Abhijit Roy ${ }^{1}$, Dr.Anup Kumar Saha ${ }^{2}$ \\ Research scholar ${ }^{I}$, Professor and Head of the Department ${ }^{2}$ \\ Department of Mechanical Engineering \\ National Institute of Technology Durgapur, Durgapur - 713209, India
}

\begin{abstract}
Steel industry uses ladle crane as a vital material handling equipment. Design and procurement of the ladle crane is not up to the mark. Type of load, height to hoist, angle of tilt, space etc ascertains the crane specification. Mathematical analysis, taking all these factors has become an important research area. Earlier researches on ladle crane dynamics are not with so details analysis and providing so many feasibilities. Simulation of Ladle Crane dynamics on ladle hoisting and ladle tilting has been discussed. A methodology to build a dynamic of ladle crane is exhibited. The methodology provided, may be used as an assistant tool is proposed so that it will help industrial designer to build or modify a ladle crane model of most technologically innovative and as per requirement and demand. Efficient and effective crane operation is the basic target of this study. A simulation study is made with different parameters to show how these influence the system's performance. A comparative study of efficient drive systems performed and from these a mathematical model is build to analyze, simulate.
\end{abstract}

Keywords- Dynamical Analysis; Crane; Modeling; Simulation;

\section{INTRODUCTION}

World without steel in recent days is beyond imagination. Steel is in every aspect of our lives. When development and growth of Infrastructural sector is critical and economies are growing faster indicates increases in steel consumption. In the developing countries economic growth is primarily indicated by how much more steel is consumed. In Steel Industry safety is always been the most important to the people or process. An Electric Overhead Travelling (EOT) crane, is vital in modern industrial environments. The Demag Cranes \& Components Corp was the first company in the world that was involved in mass-production of crane, manufactured the first steam-powered crane. In 1876 Sampson Moore of England designed the first ever electric overhead crane. Weston load brake (which is now rare) and the wire rope hoist (which is still popular), became obsolete with the progress of time. At present built-up style, hoist which is the original hoist contained components mated together is very popular. Built up hoists are generally used for long life, durability and easy maintenance. In considering the continuing safety of cranes it is important that all available information and data on the performance and operation of a crane is collected, and adequately analyzed, to identify potential impact on the structure of the crane and its future operation. As a general point of good practice our view is that the scope of thorough examination for the crane needs to be established by Safety Assurance and risk assessment, taking into account factors including design specifications, manufacturers recommendations, patterns of use, environmental factors etc. It is the usual practice that before a system is designed in details or actually built, a prototype is made as an attempt to design the system with its performance. Such prepossession is based on the mathematical depiction of the system's dynamic characteristics. This mathematical depiction is called mathematical model. Usually mathematical models of

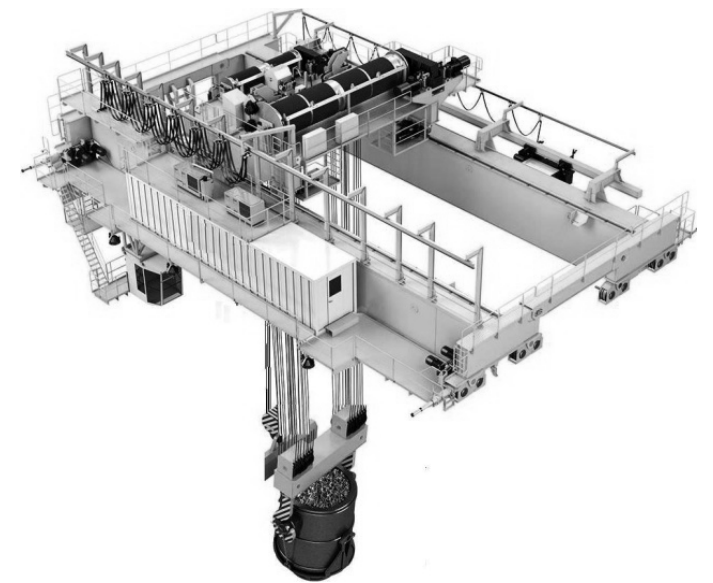

Fig.1. A typical ladle crane

physical systems are described in terms of differential equations [12]. Many different approaches have been used in the development of system models. Newton's laws for mechanics, Kirchhoff's voltage and current laws for electrical circuits such different equations are numerically solved to obtain system responses. Mathematical and/or functional correlation between the inputs and outputs of the system is expressed in terms of this compassionate in mathematical models [3]. Guidance mentions such things as independence and impartiality.

Different theoretical and experimental works [1] have established that critical or stringent dynamic stresses are incited in the crane during different operations such as load hoisting, instantaneous stop during load lowering and motion over rail joints of different kinds. A more realistic study of the dynamic behavior of crane operation and accurate estimation of dynamic stresses induced, calls for economical design of ladle cranes.

A simulation study of ladle crane dynamics and evaluation of the time response of bending stresses in the girder and rope tension during critical crane operations has been substantiated in this paper . During high-precision control of a crane The 
usual practice of decreasing the running speed was commonly espoused. Therefore, the influence caused by elastic deformation of the main beam and tensile property of the wire rope is weakened. Accuracy requirements in this approach can be satisfied to some extent, but it reduced the system's running efficiency. A system of nonlinear ordinary differential equations can be generated as state equations on the basis of Newton's laws of motion. By manipulating the state equations a simple bilinear system can be derived. During repetitive operations of load transfer, controller does not know each value of load mass, but only knows its nominal value [7]. The reliability is the prime factor which is to be considered for a ladle crane modeling. While transporting molten metal safety is also a key consideration. Taking both the issues i.e. safety and reliability very seriously, design of ladle cranes centred around redundancy of systems, ease of maintenance, and precise control. Safe transport and precise placement of the ladle along its load path which are prime requirements are done by the operator with the help of Semi automation. The goal is zero unplanned downtime of these cranes, and to develop maintenance-friendly features. We have not considered any free fall / over-speeding of the load on any part of the driving system in-between motor \& rope drum.

\section{PHySICAL MOdEL}

The crane bridge is usually constructed of two parallel girders connected across by two end carriages at the ends. The end carriages housed with the wheels, supporting the bridge

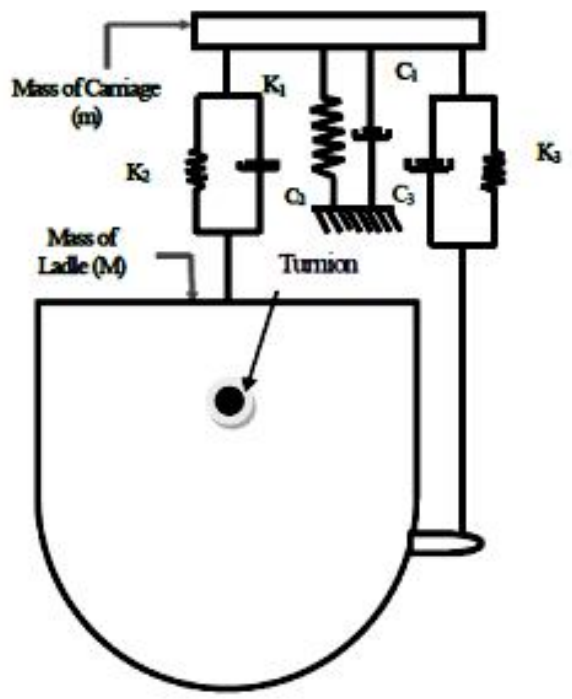

Fig. 2: Mechanical model of the Ladle

for the long travel motion, has no spring within. Depending on load capacity the bridge girders are generally constructed from built-up plate girders or rolled sections. The cross trolley moves on wheels over rails supported by the girder .Figure 1 shows the schematic diagram of a ladle crane. The hoisting, tilting, cross-travel motion of the trolley and long travel of the bridge are usually performed simultaneously. Dynamic loading of the girder of the crane during these normal operations are unavoidable. A ladle crane as shown in Fig. 1 is considered and its equivalent mechanical model has been shown in Fig 2. Following assumptions were made during modeling:

The load i.e. the ladle attached at the end of the hoisting rope has been regarded as a point mass. The Frictional torques which may exist in torque-transfer mechanisms e.g. between the sheave and rope, between the rope drum and rope, has not been taken into consideration. The ropes have been imagined to be mass less and in- extensional. The girder considered as a beam with constant rigidity and the trolley considered equivalent to a concentrated mass at the centre of the span.

\section{DYNAMICS OF LADLE CRANE}

\section{A. Kinematics}

The figure 2 represents the physical simplification of an overhead ladle crane and it is a 2 degree of freedom system. Considering the system as a lumped mass model and direction of $\mathrm{x}$-axis and $\mathrm{y}$-axis are taken as usual. A 2-degree of freedom equation can be solved by normalizing the mass, stiffness and damping constant matrices as shown in following steps:

The kinetic (KE), potential (PE) and damping (DE) energies of the entire system are as given:

$$
\begin{aligned}
& \mathrm{PE}= \frac{1}{2} \mathrm{~m}_{1}{ }^{2}+\frac{1}{2} \mathrm{M}_{2} \dot{\mathrm{x}}_{2}{ }^{2}+\frac{1}{2} \mathrm{I}^{2} \\
& \mathrm{KE}= \frac{1}{2} \mathrm{k}_{1} \mathrm{x}_{1}{ }^{2}+\frac{1}{2} \mathrm{k}_{2}\left(\mathrm{x}_{2}-\mathrm{x}_{1}-\mathrm{V}_{2} \mathrm{t}\right)^{2}+ \\
& \frac{1}{2} \mathrm{k}_{3}\left(\mathrm{x}_{3}+\mathrm{x}_{2}-\mathrm{x}_{1}-\mathrm{V}_{3} \mathrm{t}\right)^{2}+\frac{1}{2} \\
& \mathrm{DE} \mathrm{E}^{\prime}= \frac{\mathrm{d}}{\mathrm{dt}} \mathrm{DE}=\frac{1}{2} \mathrm{c}_{1} \dot{\mathrm{x}}_{1}{ }^{2}+\frac{1}{2} \mathrm{c}_{2}\left(\dot{\mathrm{x}}_{2}-\dot{\mathrm{x}}_{1}-\mathrm{V}_{2}\right)^{2}+ \\
&\left.\left.\frac{1}{2} \mathrm{c}_{3}\left(\dot{\mathrm{x}}_{3}+\dot{\mathrm{x}}_{2}-\dot{\mathrm{x}}_{1}-\mathrm{V}_{3}\right)^{2}+\frac{1}{2} \mathrm{c}_{3} \mathrm{x}_{3}+\mathrm{x}_{2}-\mathrm{x}_{1}-\mathrm{V}_{3} \mathrm{t}\right) \frac{\mathrm{D}_{1}}{2}\right]^{2} \\
& \quad\left[\left(\dot{\mathrm{x}}_{3}+\dot{\mathrm{x}}_{2}-\dot{\mathrm{x}}_{1}-\mathrm{V}_{3}\right) \frac{\mathrm{D}_{1}}{2}\right]^{2}
\end{aligned}
$$

Now let us consider the following parameters to determine /design the crane numerically.

TABLE I

PARAMETERS FOR CRANE AND LADLES 


\begin{tabular}{|c|c|c|}
\hline Dimensio & Values & Units \\
\hline $\mathbf{m}$ & 20.3 & $\mathrm{~T}$ \\
\hline $\mathbf{M}$ & 150 & $\mathrm{~T}$ \\
\hline $\mathbf{K}_{\mathbf{1}}$ & $5 / 6 \times 10^{6}$ & $\mathrm{~N} / \mathrm{m}$ \\
\hline $\mathbf{K}_{\mathbf{2}}$ & $5 \times 10^{6}$ & $\mathrm{~N} / \mathrm{m}$ \\
\hline $\mathbf{K}_{\mathbf{3}}$ & $5 \times 10^{6}$ & $\mathrm{~N} / \mathrm{m}$ \\
\hline $\mathbf{C}_{\mathbf{1}}$ & 500 & $\mathrm{Ns} / \mathrm{m}$ \\
\hline $\mathbf{C}_{\mathbf{2}}$ & 1200 & $\mathrm{Ns} / \mathrm{m}$ \\
\hline $\mathbf{C}_{\mathbf{3}}$ & 1200 & $\mathrm{Ns} / \mathrm{m}$ \\
\hline
\end{tabular}

Using Lagrange's principle of minimum potential energy for a non-conservative system and considering the value of general coordinates $\left(\mathrm{q}_{\mathrm{i}}\right)$ as $\mathrm{x}_{1}, \mathrm{x}_{2}$ and $\theta$ with static and dynamic equilibrium of the masses ' $\mathrm{m}$ ' and ' $\mathrm{M}$ ', the following equations are obtained:

$$
\begin{gathered}
\mathrm{m} \ddot{\mathrm{x}}_{1}+\mathrm{k}_{1} \dot{\mathrm{x}}_{1} \mathrm{t}+\mathrm{c}_{1} \dot{\mathrm{x}}_{1}-\mathrm{k}_{2}\left(\dot{\mathrm{x}}_{2}-\dot{\mathrm{x}}_{1}-\mathrm{V}_{2}\right) \mathrm{t}-\mathrm{c}_{2}\left(\dot{\mathrm{x}}_{2}-\dot{\mathrm{x}}_{1}-\mathrm{V}_{2}\right)- \\
\mathrm{k}_{3}\left(\dot{\mathrm{x}}_{3}+\dot{\mathrm{x}}_{2}-\dot{\mathrm{x}}_{1}-\mathrm{V}_{3}\right) \mathrm{t}-\mathrm{c}_{3}\left(\dot{\mathrm{x}}_{3}+\dot{\mathrm{x}}_{2}-\dot{\mathrm{x}}_{1}-\mathrm{V}_{3}\right) \\
=\mathrm{mg}-\left(\mathrm{F}_{1}+\mathrm{F}_{2}\right) \\
\mathrm{M} \ddot{\mathrm{x}}_{2}+\mathrm{k}_{2}\left(\dot{\mathrm{x}}_{2}-\dot{\mathrm{x}}_{1}-\mathrm{V}_{2}\right) \mathrm{t}+\mathrm{c}_{2}\left(\dot{\mathrm{x}}_{2}-\dot{\mathrm{x}}_{1}-\mathrm{V}_{2}\right)+ \\
\mathrm{k}_{3}\left(\dot{\mathrm{x}}_{3}+\dot{\mathrm{x}}_{2}-\dot{\mathrm{x}}_{1}-\mathrm{V}_{3}\right) \mathrm{t}+\mathrm{c}_{3}\left(\dot{\mathrm{x}}_{3}+\dot{\mathrm{x}}_{2}-\dot{\mathrm{x}}_{1}-\mathrm{V}_{3}\right)= \\
\mathrm{Mg}+\left(\mathrm{F}_{1}+\mathrm{F}_{2}\right) \\
{\left[\mathrm{F}_{2}+\mathrm{k}_{3}\left(\dot{\mathrm{x}}_{3}+\dot{\mathrm{x}}_{2}-\dot{\mathrm{x}}_{1}-\mathrm{V}_{3}\right) \mathrm{t}+\mathrm{c}_{3}\left(\dot{\mathrm{x}}_{3}+\dot{\mathrm{x}}_{2}-\dot{\mathrm{x}}_{1}-\mathrm{V}_{3}\right)\right]} \\
\times \frac{\mathrm{D}_{1}}{2}=\mathrm{I} \ddot{\theta}
\end{gathered}
$$

In the next step the dynamic system is decoupled. By using inverse iteration method Eigenvectors $\varphi$ is calculated. Using the eigenvectors $\varphi$ the dynamic system orthogonal coordinate can transfer so that diagonal mass matrix $[\mathrm{M}]$, diagonal stuffiness matrix $[\mathrm{K}]$, diagonal damping constant matrix [C] and respective external force $[\mathrm{P}]$ can be obtained.

Due to the difficulty to attach the hook above the centre of gravity of the ladle, vibrations are usually introduced in the system. In addition, the loaded ladles often very large and heavy, which leads to experience significant inertia forces caused by changing velocity (accelerations) during crane motions. Typically there is very little damping in the dynamic system, these vibrations can have large amplitudes.

Wire rope oscillations due to variations of motor torque considering the ladle hoisting motor to be 3-phase induction motors, the torque varies as the following:

Mass Moment of Innertia of the Loaded Ladle has been calculated with the following assumptios.

Shape of the ladle is approximated as being cylindrical with a hemispherical base of the dimensions as below:

$$
\mathrm{D}_{1}=3.04 \mathrm{~m}, \mathrm{H}=3.5 \mathrm{~m} \text {; }
$$

The walls are lined with refractory lining of uniform thickness on the sides being $t_{1}=0.25 \mathrm{~m}$, while the lining on the bottom being $t_{2}=0.30 \mathrm{~m}$. On the basis of these considerations, the moment of inertia of the ladle about its main hoist suspension point is derived below:

Mass per unit volume of empty ladle,

$$
\begin{array}{r}
\mathrm{m}_{1}=\frac{50000}{\left[\pi \mathrm{D}_{1}\left(\mathrm{H}-\frac{\mathrm{D}_{1}}{2}\right) \mathrm{t}_{1}+2 \pi\left(\frac{\mathrm{D}_{1}}{2}\right)^{2} \mathrm{t}_{2}\right]} \mathrm{Kg} / \mathrm{m}^{3} \\
=5505.4 \mathrm{Kg} / \mathrm{m}^{3}
\end{array}
$$

Now, mass per unit volume of the molten metal,

$$
\begin{array}{r}
\mathrm{m}_{2}=\frac{100000}{\left[\frac{2 \pi}{3}\left(\frac{D_{1}-2 t_{2}}{2}\right)^{3}+\pi\left(\frac{D_{1}-2 t_{1}}{2}\right)^{2} h\right]} \mathrm{Kg} / \mathrm{m}^{3} \\
=7850 \mathrm{Kg} / \mathrm{m}^{3}
\end{array}
$$

Then, $\mathrm{h}=1.77 \mathrm{~m}$

(Considering density of molten metal to be $7850 \mathrm{Kg} / \mathrm{m}^{3}$ ) or, Height of molten metal column from base of ladle $=$ $(1.77+1.52) \mathrm{m}=3.29 \mathrm{~m}$.

Moment of Inertia of the cylindrical part (which is the summation of the moment of inertia of the cylindrical molten mass and that of the ladle in the form of a hollow cylinder.

$$
\begin{array}{r}
I_{1}=\left[\frac{1}{12} \mathrm{~m}_{2} \pi\left(\frac{\mathrm{D}_{1}-2 \mathrm{t}_{1}}{2}\right)^{2} \mathrm{~h}\left(3\left\{\frac{\mathrm{D}_{1}-2 \mathrm{t}_{1}}{2}\right\}^{2}+\left\{\mathrm{H}-\frac{\mathrm{D}_{1}}{2}\right\}^{2}\right)\right] \\
\quad+\left[\mathrm{m}_{2} \pi\left(\frac{\mathrm{D}_{1}-2 \mathrm{t}_{1}}{2}\right)^{2} \mathrm{~h} \times\left\{\left(\mathrm{H}-\frac{\mathrm{D}_{1}}{2}\right)-1-\frac{\mathrm{h}}{2}\right\}^{2}\right]+\left[\frac{1}{12} \mathrm{~m}_{1} \pi\right. \\
\left.\left(\mathrm{D}_{1}-2 \mathrm{t}_{1}\right)\left(\mathrm{H}-\frac{\mathrm{D}_{1}}{2}\right) \mathrm{t}_{1}\left\{\frac{3}{4}\left(\mathrm{D}_{1}{ }^{2}+\left(\mathrm{D}_{1}-2 \mathrm{t}_{1}\right)^{2}\right)+\left(\mathrm{H}-\frac{\mathrm{D}_{1}}{2}\right)^{2}\right\}\right]
\end{array}
$$

$=46618.638 \mathrm{Kg}-\mathrm{m}^{2}$

Moment of Inertia of the hemispherical part (which is the summation of the moment of inertia of the hemispherical molten mass and that of the ladle in the form of a hollow hemisphere)

$$
\begin{aligned}
& I_{2}=\left[\frac{2}{5} m_{2} \frac{2}{3} \pi\left(\frac{D_{1}-2 t_{2}}{2}\right)^{3}\left(\frac{D_{1}-2 t_{2}}{2}\right)^{2}\right]+ \\
& {\left[\frac{2}{5} m_{1} \frac{\pi\left(D_{1}-2 t_{2}\right)^{2}}{2} t_{2} \frac{1}{4}\left\{\frac{D_{1}^{5}-\left(D_{1}-2 t_{2}\right)^{5}}{D_{1}^{3}-\left(D_{1}-2 t_{2}\right)^{3}}\right\}\right]+\left[\left\{m_{1}\right.\right.} \\
& \left.\left.\quad \frac{\pi\left(D_{1}-2 t_{2}\right)^{2}}{2} t_{2}+m_{2} \frac{2}{3} \pi\left(\frac{D_{1}-2 t_{2}}{2}\right)^{3}\right\}\left(H-\frac{D_{1}}{2}-1\right)^{2}\right]
\end{aligned}
$$

$=126985.215 \mathrm{Kg}-\mathrm{m}$ 
Total Moment of Inertia of the ladle:

$=\mathrm{I}_{1}+\mathrm{I}_{2}$

$=(46618.638+126985.215) \mathrm{Kg}-\mathrm{m}$

$=173603.853 \mathrm{Kg}-\mathrm{m}$

Considering the hoisting motors to be 3-phase induction motors $(50 \mathrm{~Hz}$.) and the torque varies as the following:

(i) 0 to 2.5 seconds operating with a variable nature.

(ii) 2.5 seconds onwards at a steady value.

From the following expressions involving power and torque delivered by the main and auxiliary hoist motors:

$$
\mathrm{V}=\frac{\pi \mathrm{DN}}{60} \mathrm{~m} / \mathrm{s} \quad, \mathrm{P}=\frac{2 \pi \mathrm{NT}}{60000} \mathrm{~kW} \quad, \quad \mathrm{~T}=\mathrm{F} . \mathrm{r}
$$

We obtain the following data from the parameters provided previously:

TABLE 2

HOIST MOTORS PARAMETERS

\begin{tabular}{|l|l|l|}
\hline Dimensions & Value & Units \\
\hline $\mathbf{P}_{\mathbf{2}}$ & 190 & $\mathrm{KW}$ \\
\hline $\mathbf{P}_{\mathbf{3}}$ & 86 & $\mathrm{Kw}$ \\
\hline $\mathbf{N}_{\mathbf{2}}$ & 595 & $\mathrm{rpm}$ \\
\hline $\mathbf{N}_{\mathbf{3}}$ & 585 & $\mathrm{rpm}$ \\
\hline $\mathbf{F}_{\mathbf{2}}$ & 7623.5 & $\mathrm{~N}$ \\
\hline $\mathbf{F}_{\mathbf{3}}$ & 5615.2 & $\mathrm{~N}$ \\
\hline $\mathbf{V}_{\mathbf{2}}$ & 0.415 & $\mathrm{~m} / \mathrm{S}$ \\
\hline $\mathbf{V}_{\mathbf{3}}$ & 0.255 & $\mathrm{~m} / \mathrm{S}$ \\
\hline
\end{tabular}

\section{B. Stresses in Wire Ropes}

By balancing of ladle direct rope tension can be obtained and for balancing the ladle following two formulas has been derivate with the assumptions mentioned above. Direct rope tensions can be obtained from balancing of the ladle with the following equations

$$
\mathrm{F}_{2}+\mathrm{F}_{3}=\mathrm{M}\left(\ddot{\mathrm{x}}_{2}-\alpha_{2} \mathrm{r}\right)+\mathrm{M}\left(\ddot{\mathrm{x}}_{3}-\alpha_{3} \mathrm{r}\right)-\mathrm{Mg}
$$

$$
\text { and } \quad \mathrm{F}_{2} \mathrm{r}=\mathrm{M}\left(\mathrm{x}_{2}-\alpha_{2} \mathrm{r}\right) \times \mathrm{r}+\mathrm{Mg} \times \mathrm{r}
$$

Simulation of the crane carried out with following parameters of hoist rope.

TABLE 3

DIMENSIONS OF HOIST ROPES \& DRUMS

\begin{tabular}{|c|c|c|}
\hline Dimensions & Value & Units \\
\hline $\mathbf{d}_{\mathbf{2}}$ & 32 & $\mathrm{~mm}$ \\
\hline $\mathbf{d}_{\mathbf{3}}$ & 26 & $\mathrm{~mm}$ \\
\hline $\mathbf{D}_{\mathbf{2}}$ & 800 & $\mathrm{~mm}$ \\
\hline $\mathbf{D}_{\mathbf{3}}$ & 500 & $\mathrm{~mm}$ \\
\hline
\end{tabular}

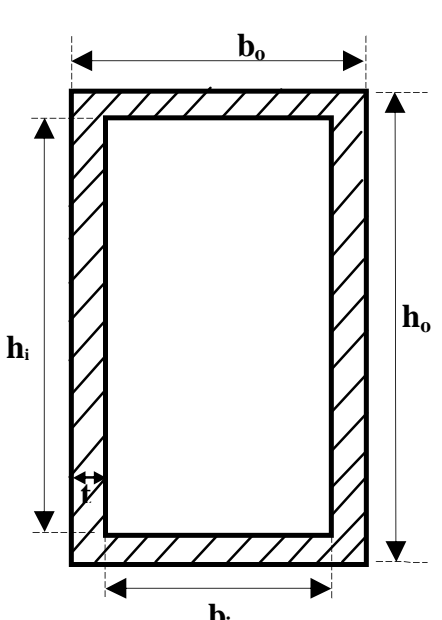

Fig. 3. Box Girder
C. Girder Stress

The structure of ladle crane is generally constructed with box girder which is nothing but girder with multiple walls, rather than an I or H-beam. These are originally constructed of riveted wrought iron; they are now presently made from rolled or welded steel. The property of better torsional resistance made box girder more favourable than usual girders for the construction of cranes.

Multiple vertical webs in box girder made it possible to increase load carrying capacity much higher than that of an I beam of equal height. For the simplicity it has been considered as a simple rectangular hollow double box girder. Applied stresses range to acceptable levels and unexpected restrained at the attachments and supports has been avoided. Assumed that there is no stress concentration at the critical locations and minimizing residual stresses.

From the bending stress formula: $\sigma_{g}=\frac{M}{2 Z}$

TABLE 4

GIRDER CALCULATION

\begin{tabular}{|l|l|l|}
\hline Dimensions & Values & Units \\
\hline $\mathrm{b}_{\mathrm{o}}$ & 400 & $\mathrm{~mm}$ \\
\hline $\mathrm{h}_{\mathrm{o}}$ & 1500 & $\mathrm{~mm}$ \\
\hline $\mathrm{b}_{\mathrm{i}}$ & 350 & $\mathrm{~mm}$ \\
\hline $\mathrm{h}_{\mathrm{i}}$ & 1450 & $\mathrm{~mm}$ \\
\hline $\mathrm{t}$ & 25 & $\mathrm{~mm}$ \\
\hline $\mathrm{w}$ & 1020 & $\mathrm{Kg} / \mathrm{m}$ \\
\hline $\mathrm{EI}$ & 16634864580 & $\mathrm{~N}-\mathrm{m}^{2}$ \\
\hline $\mathrm{Z}$ & 0.1108 & $\mathrm{~m}^{3}$ \\
\hline $\mathrm{L}$ & 22 & $\mathrm{~m}$ \\
\hline
\end{tabular}

\section{RESULTS AND DISCUSSION}

Graphical plots obtained are as follows:

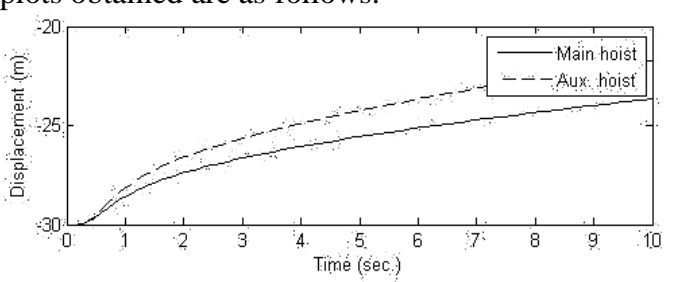

Fig. 4. Hoisting displacement vs. Time of main and auxiliary hoist 


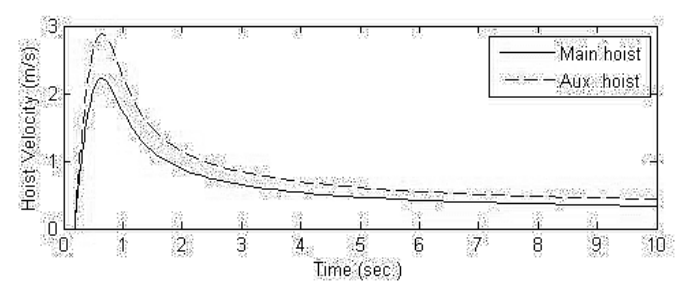

Fig. 5. Hoisting velocity vs. Time of main and auxiliary hoist

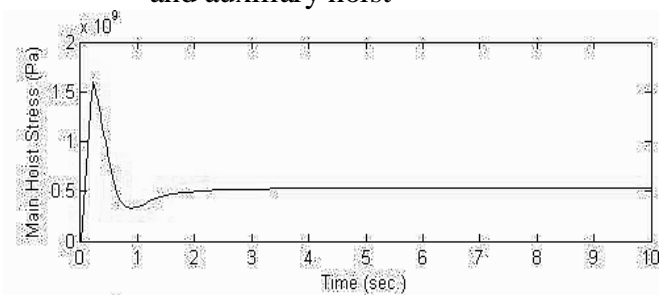

Fig. 6. Main Hoist Stress vs. Time

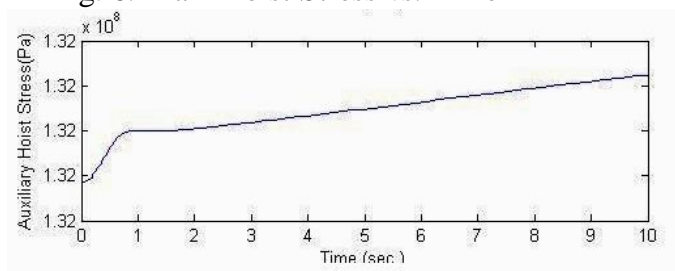

Fig. 7. Auxiliary Hoist Stress vs. Time

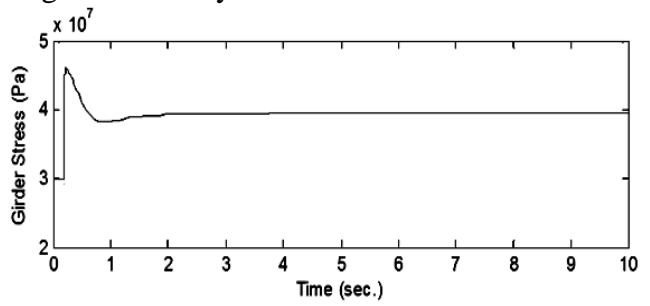

Fig. 8. Girder Stress vs. Time

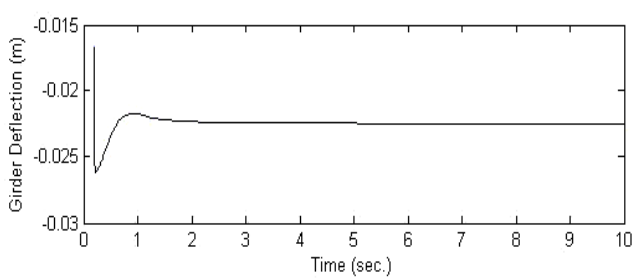

Fig. 9. Girder Deflection vs. Time

\section{CONCLUSION}

In this paper a Mathematical Model has been developed, to analyze Ladle Crane Dynamics for its economic design. The Model honeycomb includes hoisting and tilting of the ladle. This paper proposed a simplified formula and the MATLAB software has been utilized for numerical computation and visualization. Based on the analysis of the ladle crane, taking ladle inertia into consideration and parametric values collected from different ladle cranes of steel plant units which are in good working condition Fig. 8.shows that girder stress increases with the progress of time i.e. with increase of hoisting distance .It is to be noted that the plots (Figs 4-9) clearly represents an over-damped system. Simulation results in Fig. 6 and Fig. 7 depicts that the Main and Auxiliary hoist wire ropes undergo a maximum stress of $1.6 \mathrm{GPa}$ and $132 \mathrm{MPa}$ respectively against a failure limit of $1.96 \mathrm{GPa}$. The Girder stress peaks at $46.13 \mathrm{MPa}$ which is consistency with that of permissible limit according to design rules. The untoward change in the Fig. 6. can be explained by the torque variation of motors as well as transition of load on the rope. Simulation results represents, little bit transit behavior in the velocities vs. time graphs of two ropes in Fig. 5 can be convoluted as, at beginning due to clean jerk, the two ropes face at the moment when ladle starts to move upward from rest and velocity in two cases decreases all on a sudden, after that more or less constant velocity is maintained. There is further scope of design and development the ladle crane considering swing motion of the ladle in control and can also be considered from graphical analysis methods.

\section{NOMENCLATURE :}

$\mathrm{M}=$ mass of the loaded ladle

$\mathrm{m}=$ mass of the crane trolley

$\mathrm{Z}=$ section modulus of the girder

$\mathrm{c}=$ general damping constant

$\mathrm{k}=$ general stiffness constant

$\mathrm{k}_{1}=$ stiffness of the girder

$\mathrm{k}_{2}=$ stiffness of main hoisting rope

$\mathrm{k}_{3}=$ stiffness of auxiliary hoisting rope

$\mathrm{V}_{2}=$ velocity of the main hoist rope

$\mathrm{V}_{3}=$ velocity of the auxiliary hoist rope

$\mathrm{T}_{2}=$ torque transmitted by main motor

$\mathrm{T}_{3}=$ torque transmitted by auxiliary motor

$\mathrm{P}_{2}=$ power of main motor

$\mathrm{P}_{3}=$ power of auxiliary motor

$\mathrm{d}_{2}=$ diameter of the main hoist rope

$\mathrm{d}_{3}=$ diameter of the auxiliary hoist rope

$\alpha_{2}=$ torque to inertia of main motor

$\alpha_{3}=$ torque to inertia of auxiliary motor

$\mathrm{D}_{2}=$ diameter of the main hoist drum

$\mathrm{D}_{3}=$ diameter of the auxiliary hoist drum

$\sigma_{\mathrm{b}}=$ bending stress on ropes

$\mathrm{t}_{1}=$ thickness of refractory wall at cylindrical part of ladle

$\mathrm{t}_{2}=$ thickness of refractory wall at hemispherical part of ladle

$\mathrm{h}=$ Height of the liquid metal column

$\mathrm{c}_{1}=$ damping constants of the girder structure

$\mathrm{c}_{2}=$ damping constant of main hoisting rope

$c_{3}=$ damping constant of auxiliary hoisting rope respectively

$\mathrm{x}_{1}=$ vertical displacement of joist/ girder

$\mathrm{x}_{2}=$ displacement of point where main hoist is attached to

ladle

$\mathrm{x}_{3}=$ displacement of point where auxiliary hoist is attached to ladle

$\dot{\mathrm{x}}_{2}=$ hoisting velocity of point where main hoist is attached to ladle 
$\dot{\mathrm{X}}_{3}=$ hoisting velocity of point where auxiliary hoist is

attached to ladle

$\theta=$ angle of tilt of the ladle with respect to horizontal axis

$\mathrm{E}=$ elastic modulus of girder material

$\mathrm{E}_{\mathrm{I}}=$ flexural rigidity of the girder

$\mathrm{F}_{2}=$ force on main hoist rope

$\mathrm{F}_{3}=$ force on auxiliary hoist rope

$\mathrm{L}=$ girder span

$\mathrm{D}_{1}=$ diameter of the ladle

$\mathrm{r}=$ radius of the ladle

$\mathrm{H}=$ height of the ladle

$\sigma_{\mathrm{g}}=$ bending stress on the girder

\section{References}

[1] Lanfeng $\mathrm{Yu}^{*}$, Calculation method and control value of static stiffness of tower crane, Journal of Mechanical Science and Technology 22 (2008) $829 \sim 834$.

[2] QuangHieu Ngo, Keum-Shik Hong, and Il HyoJung, Adaptive control of an axially moving system, Journal of Mechanical Science and Technology 23 (2009) 3071 3078.

[3] QuangHieu Ngo and Keum-Shik Hong, Skew control of a container crane, Journal of Mechanical Science and Technology 23 (2009) $3332 \sim 3339$.

[4] Ranjit Karmakar and A.Mukherjee, Dynamics of Electric Overhead Travelling Cranes, Mech.Mach.Theory Vo. 25-25No. 1pp29-39, 1990.

[5] E. Lightfoot, Shock loading effects in overhead travelling cranes-review of dynamic stress allowances. Engng 181, 169(1956).

[6] Yoshiyuki Sakawa and Hideki Sano, Nonlinear Model and Linear Robust Control of Overhead Travelling Cranes ,pp2197-2207 PII: SO362546X (97)00107-7,

[7] E.Lightfoot, B.L.Clarkson, Proceedings of the Institution of Mechanical Engineers June 1955 169: 233-25(1955).

[8] E.M. Abdel-Rahman, A.H. Nayfeh, Z.N. Masoud, Dynamics and control of cranes: a review; Journal of Vibration and Control, 9 (7) (2003), pp. 863-908.

[9] D.C.D. Oguamanam, J.S. Hansen, G.R. Heppler, Dynamics of a threedimensional overhead crane system; Journal of Sound and Vibration, 242 (3) (2001), pp. 411-426.

[10] S. Kiliceaslan, T. Balkan, S.K. Ider, Tipping loads of mobile cranes with flexible booms; Journal of Sound and Vibration, 223 (4) (1999), pp. 645-657.

[11] R.M. Ghigliazza, P. Holmes, on the dynamics of cranes, or spherical pendulum with moving supports; International Journal of Non-Linear Mechanics, 37 (6) (2002), pp. 1211-1221

[12] Katsuhiko Ogata, System Dynamics Fourth Edition, 2004, 1998, 1992, 1978 Pearson Education, Inc.Pearson Prentice Hall, pp 2, ISBN D-13$1424 b 2-9$

[13] Lingzhi Cao, Liping Lu, Guangzhao Cui, Shangbei Wei, Feipeng Lou, Weipu Miao, Sequential modeling and control of the dynamic load in crane lifter, pp 4844-48482009 Chinese Control and Decision Conference (CCDC 2009)
[14] Julius P. Van De Pas and James M. Fisher, Crane Girder Design, PP 4857 in Modern Steel Construction, March 1996. 